\title{
Changing attitudes: supporting teachers in effectively including students with emotional and behavioural difficulties in mainstream education
}

\author{
Geraldine Scanlon $^{\mathrm{a} *}$ and Yvonne Barnes-Holmes ${ }^{\mathrm{b}}$ \\ ${ }^{a}$ School of Education Studies, Dublin City University, Glasnevin, Dublin 11, Ireland; ${ }^{b}$ Department \\ of Psychology, The National University of Ireland, Maynooth, Co. Kildare, Ireland
}

\begin{abstract}
Pupils with emotional and behavioural difficulties (EBD) are often considered the most challenging group to manage within mainstream education. The challenges perceived by teachers may be due, in part, to negative attitudes towards this cohort of pupils, which may exacerbate feelings of inadequacy and impact negatively upon direct interactions with pupils. The current study comprised a combination of implicit (i.e. the Implicit Relational Assessment Procedure, IRAP) and explicit (The Opinions Relative to Mainstreaming Scale, ORMS) technologies to assess the attitudes of teachers $(N=25)$ and teachers in training $(N=20)$ towards pupils with EBD. When these attitudes proved to be negative (relative to typically developing pupils), the utility of a combined behaviour intervention (BI) and stress-management intervention (SMI), in conjunction with a series of pre and post measures, was examined. The IRAP results for teachers indicated that the SMI enhanced their implicit positivity towards pupils with EBD (EBD PUPIL) to a considerable extent (0.025-0.175), and this was greater than the impact recorded with the BI. The teachers in training showed implicit negativity towards EBD PUPIL (0.13) and this decreased, albeit marginally, at post-BI $(0.05)$ and post-SMI (0.06). Significant differences were recorded in teachers' general attitudes towards inclusion $(p<0.001)$ and efficacy $(p<0.008)$. Significant effects were recorded for teachers in training in relation to their attitudes towards having a child with EBD and having a previously excluded child with EBD in their classrooms (all $p$ s $<0.001$ ). For this latter group, reductions were also recorded in their levels of depression, anxiety and stress $(p<0.001)$ and there was an increase in their psychological flexibility $(p<0.001)$. The current results indicate that a range of positive implicit and explicit outcomes was associated with the current BI and SMI package in terms of fostering more effective inclusion of pupils with EBD in mainstream education.
\end{abstract}

Keywords: emotional and behavioural difficulties; attitudes; mainstream education; stress management; behavioural management

\section{The context}

Consistent with international efforts towards the inclusion of pupils with special educational needs (SEN) in mainstream education, the Irish education system has witnessed significant change in this regard in the last decade. Relevant national legislation directing this change includes The Special Education Review Committee (SERC) 1993, The Education Act (1998) and the Education for Persons with Special Educational Needs

\footnotetext{
*Corresponding author. Email: Geraldine.scanlon@dcu.ie
} 
[EPSEN] Act (2004). One of the most significant implications of the EPSEN Act is that some pupils with diagnosed SEN fall under the remit of teachers in mainstream education. This new responsibility and related demands have been the catalyst for broad consensus that the process of inclusion in Ireland has occurred too quickly and without adequate preparation (Task Force on Behaviour 2006; Travers 2006).

\section{Defining emotional and behavioural difficulties}

Although the EPSEN Act (2004) collectively refers to all children with SEN, the Department of Education and Skills (DES) sub-categorises on the basis of educational and resource implications. The most demanding sub-groups on these bases include pupils with EBD, attention deficit/hyperactivity disorder (ADHD), oppositional defiant disorder (ODD) and conduct disorder (CD). As a result, the challenges associated with these subgroups of SEN do not result necessarily from impaired intellectual functioning, but rather from the presence of challenging behaviour (Bay and Bryan 1991; Nitnas et al. 2006).

In spite of significant attention in the literature, there remains a lack of consensus on a working definition of EBD (SERC 1993; Evans, Harden, and Thomas 2004; Task Force on Behaviour 2006; Cooper and Jacobs 2011). This lack of agreement is underpinned by different views on the origins of the difficulties - as within-child variables or as a socially mediated phenomenon. The medical model that encapsulated the traditional definition of EBD is consistent with the former, whereas the contemporary view describes a more context-based set of problems that arise within specific situations and environments (Daniels, Cole, and Reykebill 1999; Evans, Harden, and Thomas 2004). Nonetheless, the diagnosis retains a mental health perspective, in which outwardly disruptive behaviour is associated with internal malaise (Task Force on Behaviour 2006). The often profound implications for the individual with EBD and those around them are aptly summarised in the SERC (1993) definition:

Emotional and/or behavioural disorder can be defined as an abnormality of behaviour, emotions or relationships, sufficiently marked and prolonged to cause handicap in the individual pupil, and/or serious distress or disturbance in the family, the school or community (p. 132).

\section{Within-school variables: teachers' attitudes to pupils with EBD}

It is widely accepted that the success of inclusive policies for the education of children with SEN depends upon a number of teacher-related variables, including generic attitudes to inclusion (Avramidis and Norwich 2002; Hastings and Oakford 2003) and skills in managing these populations (Lambe and Bones 2006). In particular, teachers' self-perceptions of competence are influenced by levels of resources (Butler and Shevlin 2001) which are all too often described as inadequate (Scanlon and McGilloway 2006).

A number of pupil-based variables appear, in turn, to influence teachers' attitudes to inclusion (Clough and Lindsay 1991; Scruggs and Mastropieri 1996). For example, pupils with EBD are often viewed as the most challenging and rank highly among the sub-sets of pupils with SEN whom teachers consider to be potentially unsuitable for inclusion in mainstream education (Avramidis and Norwich 2002). This perceived unsuitability is strongly influenced by the recurrence of problem behaviour. Specifically, these pupils are among those most commonly involved in daily school misdemeanours, such as office discipline referrals (Larsen, Steele, and Sailor 2006); they are most likely to participate in restrictive 
and exclusionary educational practices (Kauffman 1999); and they have disproportionately high rates of school dropout and academic failure (Larsen et al. 2006). Taken together, these findings highlight the challenges faced by teachers in managing and educating pupils with EBD, especially in mainstream classrooms (see Scott 2007).

It is not surprising that teachers perceive direct interactions with pupils with EBD as tense and often aversive (Sutherland et al. 2008), with the implications of such interactions including higher rates of teacher depression and burnout (Hastings and Bham 2003). The far-reaching implications of these relationships for teachers are aptly summarised by Griffin and Shevlin (2007):

Teachers are just as vulnerable as children to the loss of self-esteem, particularly if they experience an abiding sense of failure when support is not forthcoming. (p. 104)

\section{Teachers' implicit cognitions}

Several theoretical models may account for the processes by which teachers' expectations and attitudes are communicated to pupils. For example, Greenwald and Banaji (1995) defined an implicit attitude as:

... introspectively unidentified (or inaccurately identified) traces of past experience that mediate favourable or unfavourable feeling, thought or action toward social objects. (p. 8)

Although implicit attitudes are often activated automatically (i.e. without conscious knowledge), they nonetheless influence overt action. This paradox is reflected in the fact that individuals often do not attempt to control this action, because they do fully appreciate its relationship with their implicit attitudes.

Related recent research by the current authors specifically attempted to explore teachers' implicit attitudes to pupils with EBD, using a type of implicit technology known as the IRAP (Barnes-Holmes et al. 2006; Scanlon et al. submitted). The IRAP is a response latency-based computer task in which participants respond quickly and accurately to simple word pairings that are consistent or inconsistent with their social histories. In simple terms, the methodology predicts that on average, participants will respond more quickly to pairings that reflect well-established beliefs than to those that do not, and the IRAP assesses the response latency differences between these. Numerous published studies attest to the utility of this measure for the study of socially sensitive attitudes, including teachers' attitudes to pupils, preference for social groups (Power et al. 2009), attitudes to body image (Roddy, Stewart, and Barnes-Holmes 2010) and ageism (Cullen et al. 2009). The research by Scanlon et al. (submitted) employed an IRAP that juxtaposed TEACHER and EBD PUPIL, in conjunction with positive and negative terms. The results indicated that teachers showed strong implicit positivity towards TEACHER but implicit negativity towards EBD PUPIL, and yet teachers openly expressed positive views on the inclusion of pupils with SEN in mainstream education, as measured on the explicit ORMS.

\section{Changing teacher attitudes}

The research reviewed thus far suggests two issues with the potential to hamper the effective inclusion of pupils with EBD in mainstream education. First, negative teacher attitudes may exacerbate feelings of inadequacy and impact negatively upon direct interactions with 
pupils; second, a lack of specific training and support for teachers in this regard may reduce opportunities for positive interactions and increase the possibility of negative interactions. Taken together, these two issues suggest the need for a broad approach to the challenges faced by teachers, especially in the context of EBD. That is, one potential solution to the difficulties that emerge for teachers in interacting with pupils with EBD is to address both behavioural and psychological factors.

\section{On the behavioural side}

School-wide positive behaviour support (SWPBS) has been defined as the "the application of positive behavioural intervention and systems to achieve socially important behaviour change' (Sugai et al. 2000, 133), and is currently implemented in more than 4000 US schools as a means of addressing problem behaviour. This system is often characterised by the use of individual student behaviour support plans (Luiselli et al. 2005) and has a number of critical components that are applied behaviour analytic (ABA) in origin: (1) consensusdriven behaviour expectations must be established; (2) critical interpersonal skills must be targeted; (3) there must be systematic positive reinforcement for meeting and exceeding performance criteria; (4) intervention efficacy must be monitored continuously through data collection and analysis; (5) all relevant parties (pupils, teachers, administrators and parents) must participate in the processes of behaviour change; (6) reactive, punitive and exclusionary strategies should be reduced in favour of a proactive, preventive and skillbuilding orientation. Preliminary outcome data suggest that the implementation of this system is associated with a decrease in school-wide problems, as well as the creation of a positive school climate (Cohen, Kincaid, and Childs 2008).

\section{On the psychological side}

As a profession, teachers report high rates of work stress and burnout (Talmor, Reiter, and Feigin 2005), which may be exacerbated by tense relationships with pupils with SEN, especially those with whom there is an increased probability of challenging behaviour (Sutherland et al. 2008). According to Lazarus and Folkman (1984), the negative effects of work-related stress may be reduced through problem-focused stress-management interventions that specifically target undesirable thoughts and emotions and explore their impact on work-related behaviour. In a similar vein, Bond and Bunce (2000) used techniques from acceptance and commitment therapy (ACT; Hayes et al. 2006) to successfully reduce workrelated stress and significantly improve the general mental health of participants. A total of 90 participants were randomly allocated to an ACT $(n=30)$ group which sought to enhance their ability to cope with work-related strain, an Innovation Promotion Program $(n=30)$ that helped individuals identify and consequently innovatively change causes of occupational strain or a waitlist control group $(n=30)$. Improvements in mental health and work-related variables were found following both interventions; however, as hypothesized by the authors, improvement in the general mental health of participants was found to be mediated specifically by the acceptance of undesirable thoughts and feelings, and their unwanted influence on behaviour. This was measured by utilising the Acceptance $\&$ Commitment questionnaire, a 16-item measure that assesses participants' ability to accept their undesirable thoughts and feelings while still pursuing the goals that they wish to achieve (e.g. 'It's ok to feel depressed or anxious'). The positive outcomes in this research demonstrated the utility of confronting and accepting one's own thoughts and attitudes and highlighted the likely link between internal content and external behaviour. 


\section{The current research}

The research reported in the current paper had two core aims. First, a combination of implicit and explicit technologies was used to assess the attitudes of teachers $(N=25)$ and teachers in training $(N=20)$ towards pupils with EBD. The authors were interested in how both groups of teachers viewed pupils with EBD in mainstream education and how, in turn, this might affect their daily interactions with these pupils in the classroom. Comparing these two groups might also highlight the optimum point within the teaching career at which to intervene: for example, if better results were to be obtained with the teachers in training, this would indicate that early intervention is advisable. Second, when these attitudes proved to be negative (relative to typically developing pupils), we examined the utility of a combined behavioural and psychological intervention package. The behavioural component, referred to as the Behavioural Intervention (BI), utilised elements of SWPBS to enhance participants' knowledge and skills regarding challenging behaviour. The psychological component, referred to as the Stress Management Intervention (SMI), explored participants' school-related challenges and the impact of these on their personal and professional lives. Acceptance-based strategies were then employed as a means of reducing stress and enhancing self-efficacy.

\section{Method}

\section{Participants}

All students registered for a postgraduate diploma in education at an Educational Institution (i.e. teachers in training for secondary education) were contacted by email and invited to participate, resulting in a 20-person sample. Post-primary schools in the Leinster region of Ireland were contacted to invite teachers in their respective schools to participate in the study. Interested participants $(n=40)$ were then invited to a meeting about the project and informed about the level of participation and commitment that would be required. This resulted in a final sample of 25 mainstream post-primary teachers.

\section{Setting}

For logistical reasons, some aspects of participation were conducted at the university, while others were conducted in participants' schools.

\section{Materials}

\section{Explicit measures for the BI}

The revised ORMS by Antonak and Larrivee (1995) assessed teachers' attitudes to the generic concept of disabilities and the potential for inclusion in mainstream education. For the purposes of the current study, the ORMS was modified to fit the Irish context and to examine specific attitudes to the inclusion of pupils with EBD. Scoring the ORMS did not generate an overall result but comprised the scores from each of three sub-scales, which were composites of individual scores on each item. In all cases, a higher score indicated a more positive attitude. One sub-scale assessed attitudes to the general inclusion of children with EBD across 12 items (e.g. 'The needs of students with EBD are best served through special separate classes'). Respondents indicated dis/agreement with each item on a five-point scale that ranged from $1=$ strongly disagree to $5=$ strongly agree. A second sub-scale assessed emotional reactions to the inclusion 
of pupils with EBD within participants' classrooms. The sub-scale presented two short scenarios (e.g. 'If a new student who was described as having severe behavioural problems was due to join your class tomorrow, you would feel . . ') in conjunction with seven bipolar adjectives (uncomfortable/comfortable; negative/positive; unconfident/confident; pessimistic/optimistic; worried/self-assured; disinterested/interested; unhappy/happy). Participants rated their reactions to each scenario on a seven-point scale from 1 (e.g. uncomfortable) to 7 (e.g. comfortable). The third sub-scale measured participants' willingness to adapt their teaching practices to include children with EBD. This scale comprised eight items (e.g. 'I would be supportive towards the idea of including children with emotional and behavioural difficulties in my classroom'), against which participants rated their dis/agreement with each item on a five-point scale that ranged from $1=$ strongly disagree to $5=$ strongly agree.

\section{Explicit measures for the SMI}

The Teachers' Sense of Efficacy Scale (TES) examined teachers' self-reported efficacy with regard to the three dimensions of student engagement, instructional practices and classroom management (Tschannen-Moran and Woolfolk-Hoy 2001). The TES comprises 12 items (four per dimension) which participants scored according to their level of agreement from $1=$ strongly agree to $6=$ strongly disagree. Item scoring generated an overall score; a higher score indicated a greater sense of teacher efficacy.

The Depression Anxiety Stress Scales (DASS) measured current levels of general depression, anxiety and stress (Lovibond and Lovibond 1995). The 21-item measure (seven items for each of the three sub-scales) required responses on a four-point scale of applicability that ranged from $0=$ did not apply to me at all to $4=$ applied to me very much or most of the time on items such as 'I felt I had nothing to look forward to'. Applicability referred to the extent to which participants had experienced each state in the past week. The sub-scale mean scores for a normative sample are: 6.14-6.55 for depression; 4.6-4.8 for anxiety; and 9.93-10.29 for stress (Crawford and Henry 2003).

The Acceptance and Action Questionnaire (AAQ-II) was a self-report measure of psychological flexibility (Bond et al. 2011). The 10 items assessed acceptance (e.g. 'It's ok if I remember something unpleasant') vs. avoidance ('My painful experiences and memories make it difficult for me to live a life that I would value'). Responses were provided on a 7 -point scale that ranged from $1=$ never true to $7=$ always true. The avoidance items were reverse scored. Total scores ranged from 10 to 70, with high scores indicating high acceptance/low avoidance and low scores representing low acceptance/high avoidance. The mean for a sample of university students is 50.72 (Bond et al. 2011).

The Maslach Burnout Inventory (MBI) assessed three aspects of burnout syndrome: emotional exhaustion (EE), depersonalisation (Dp) and lack of personal accomplishment (PA; Maslach, Jackson, and Leiter 1996). Each of the three sub-scales contained 22 statements of job-related feelings. The EE sub-scale assessed feelings of being emotionally overextended and exhausted by one's work (e.g. 'I feel emotionally drained from my work'). Respondents indicated feeling frequency per statement on a scale from $0=$ never to $6=$ everyday. The Dp sub-scale measured an unfeeling and impersonal response toward recipients of one's service, care, treatment, or instruction (e.g. 'I worry that this job is hardening me emotionally'). The PA sub-scale assessed feelings of competence and successful achievement in one's work with people (e.g. 'I feel very energetic'). Burnout is conceptualised as a continuous variable, ranging from a low/moderate to a high degree of 
experienced feeling. High burnout is reflected in high EE and high Dp, but low PA scores. Moderate burnout is reflected in moderate scores on all three sub-scales. Low burnout is reflected in low EE and low Dp scores, with high PA scores. Means recorded with teachers are EE: 21.25, Dp: 11, PA: 33.54, indicating slightly higher EE, substantially higher Dp and lower PA than other occupational groups (Maslach, Jackson, and Leiter 1996).

\section{Apparatus}

The IRAP is a computer program written in Visual Basic, which controls all aspects of stimulus presentation and the recording of all participant responses. The stimuli presented throughout the IRAP comprised three groups of words. The sample stimuli comprised the word PUPIL and the phrase EBD PUPIL (capital letters indicate actual words as they appeared onscreen). The target stimuli comprised 12 evaluative terms: six positive (ACCOMODATING, SUITABLE, CO-OPERATIVE, PLEASANT, CALM and POSITIVE) and six negative (DIFFICULT, NON-COMPLIANT, ANGRY, NEGATIVE, UNPLEASANT and INAPPROPRIATE). The response options comprised the two relational terms SIMILAR and OPPOSITE.

The IRAP employed here was constructed according to four basic trial-types (see Figure 1), referred to as PUPIL/Positive (top left); EBD PUPIL/Negative (top right); EBD PUPIL/Positive (bottom left); and PUPIL/Negative (bottom right). Each block of IRAP trials comprised 12 exposures to each of these four trial-types. The locations of SIMILAR and OPPOSITE were randomised across trials.

Consistent Trial (PUPIL/Positive)

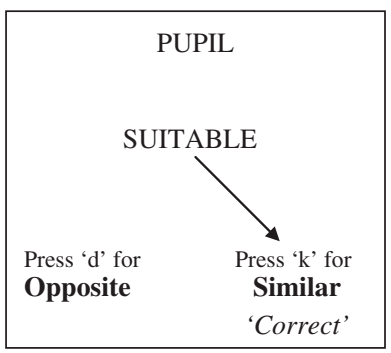

Consistent Trial (EBD PUPIL/Positive)

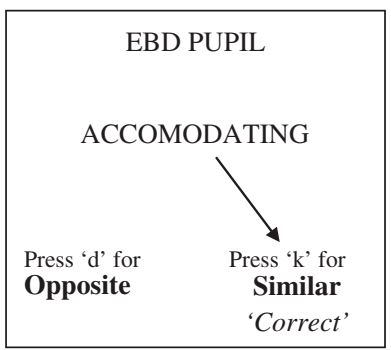

Consistent Trial (EBD PUPIL/Negative)

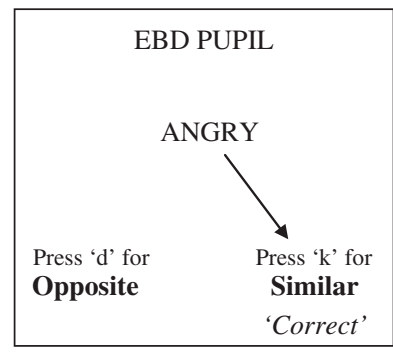

Consistent Trial (PUPIL/Negative)



Figure 1. An example of each of the four IRAP trial-types as consistent responding. (Note that the word 'CORRECT' did not appear onscreen at any point). 


\section{Experimental sequence}

All participants received three separate exposures to the IRAP and the explicit measures: pre-intervention 1 ; post-intervention 1 /pre-intervention 2 ; and post-intervention 2 (see Figure 2). This sequence was intended to assess the relative and combined impacts of the interventions. Furthermore, the actual sequencing of the interventions was counterbalanced within each group (i.e. half of the teachers in training did the BI first and the SMI second and the other half followed the reverse order). This was also the case for the teachers.

\section{Procedure}

\section{The IRAP}

The IRAP systematically juxtaposed consistent vs. inconsistent trials in an alternating block sequence. Consistent trials comprised associating PUPIL with positive words and EBD PUPIL with negative words (e.g. PUPIL-SUITABLE-SIMILAR; PUPIL-ANGRYOPPOSITE; EBD PUPIL-SUITABLE-OPPOSITE; and EBD PUPIL-ANGRY-SIMILAR). Inconsistent trials comprised associating PUPIL with negative words and EBD PUPIL with positive words (e.g. PUPIL-SUITABLE-OPPOSITE; PUPIL-ANGRY-SIMILAR; EBD PUPIL-SUITABLE-SIMILAR; and EBD PUPIL-ANGRY-OPPOSITE). In short, responses on consistent trials were expected to be biased towards PUPIL and against EBD PUPIL, but the reverse was the case for responses on inconsistent trials (see Figure 1).

\section{The BI}

The BI comprised four two-hourly lectures presented across a block of four consecutive weeks. The content and structure of the intervention were derived from an SWPBS model and are summarised in (Table 1). The intervention provided specific information on the cognitive and behavioural difficulties associated with the variety of disorders that present along the EBD continuum, as well as the manner in which these impact upon pupil learning capabilities and upon the teacher. The overarching aim was to enable teachers to incorporate EBD pupils more effectively into their mainstream classrooms (e.g. by minimising behavioural disruption and increasing reinforcing interactions).



Figure 2. Experimental sequence. 
Table 1. Core components of the BI.

Core components of the BI

Categories of EBD

Characteristics and difficulties associated with EBD

The relationship between emotional/cognitive deficits and learning/behaviour

A whole school-based approach to discipline: 'What Works'

An introduction to the framework of ABA

Basic principles

Positive and negative reinforcement

Identification of behaviours

Observation and assessment

Intervention strategies for challenging behaviour

Developing a school-wide approach

Table 2. Core components of the SMI.

Core components of the SMI

Focus on thoughts

Negative thoughts

Write down your worst thought

Strategies you engage in to avoid negative thoughts

Who are you and what motivated you to become a teacher?

Realignment with personal values

The primary aim of the BI was to enable participants to examine potentially effective policies and procedures applicable to their pupils and school contexts. Participants were encouraged to explore the strategies currently available, as well as developing alternative methods by incorporating the ABA framework. As part of the intervention, participants completed a 30-minute videotaped observation of a classroom situation in which they were experiencing difficulties with behavioural issues. Each participant then received feedback on this situation.

\section{The SMI}

The SMI comprised a one-day workshop derived from the core principles of ACT, which are summarised in Table 2. This emotion-focused intervention attempted to teach participants to accept negative thoughts and feelings in the service of achieving values. Much of the content of the intervention centred on participants' reactions to children with behavioural challenges and the impact of these on the educational environment, as well as exploring their commitment to teaching and general self-efficacy.

\section{Results}

The current research had two core aims. First, we employed a combination of implicit and explicit technologies to assess the attitudes of mainstream teachers and teachers in training towards pupils with EBD. Second, when these attitudes proved to be negative (relative to typically developing pupils), we examined the utility of a combined behavioural 
and psychological intervention package. In short, we predicted that participants would harbour negative thoughts about pupils with EBD, but that these would become less stressful and less obstructive when addressed openly. We also assumed that specialist training in behavioural principles and practices for dealing with challenging behaviour would reduce the occurrence of these behaviours and ultimately enhance self-efficacy in educating pupils with EBD.

\section{IRAP results}

The IRAP software records accuracy and response latencies on every trial. Accuracy is defined as the first response and is used as a screening mechanism to exclude participants whose accuracies fall below $80 \%$. Response latency is defined as the time (in ms.) between the onset of a trial and the emission of a correct response. Consistent with published IRAP research (e.g. Cullen et al. 2009 ), the response latency data for each participant were transformed into a $D$-score, which represents the difference between consistent and inconsistent responding. In order to compare responding on the four main trial-types, the D-scores were then transformed into DIRAP-(trial-type) scores, which were then collapsed according to trial-type to generate a D-score for each trial-type (PUPIL vs. EBD PUPIL). The results obtained with the teachers in training on each of the three IRAP exposures (baseline, post-BI and post-SMI) are presented in Figure 3.

On the baseline IRAP, the teachers in training showed strong positivity towards PUPIL, but not towards EBD PUPIL. Neither intervention had any notable impact on the latter in terms of enhancing positivity towards EBD PUPIL. Interestingly, however, both

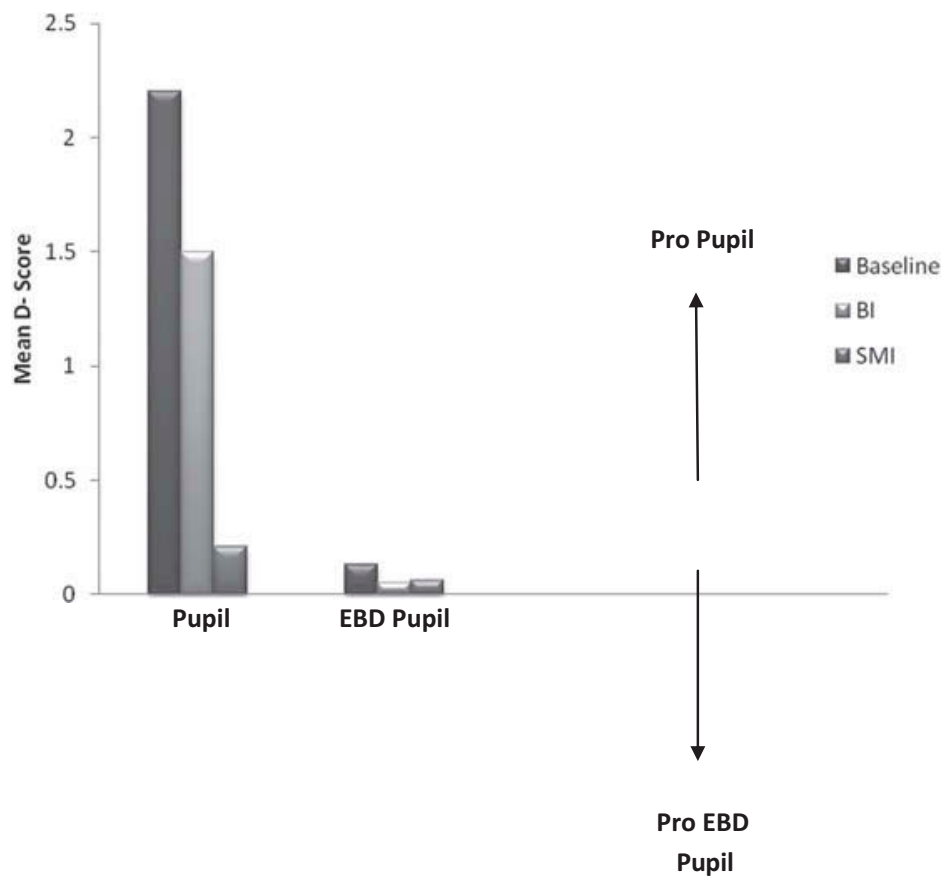

Figure 3. Mean D-scores for teachers in training on the PUPIL and EBD PUPIL trial-type pairs on each IRAP exposure. 


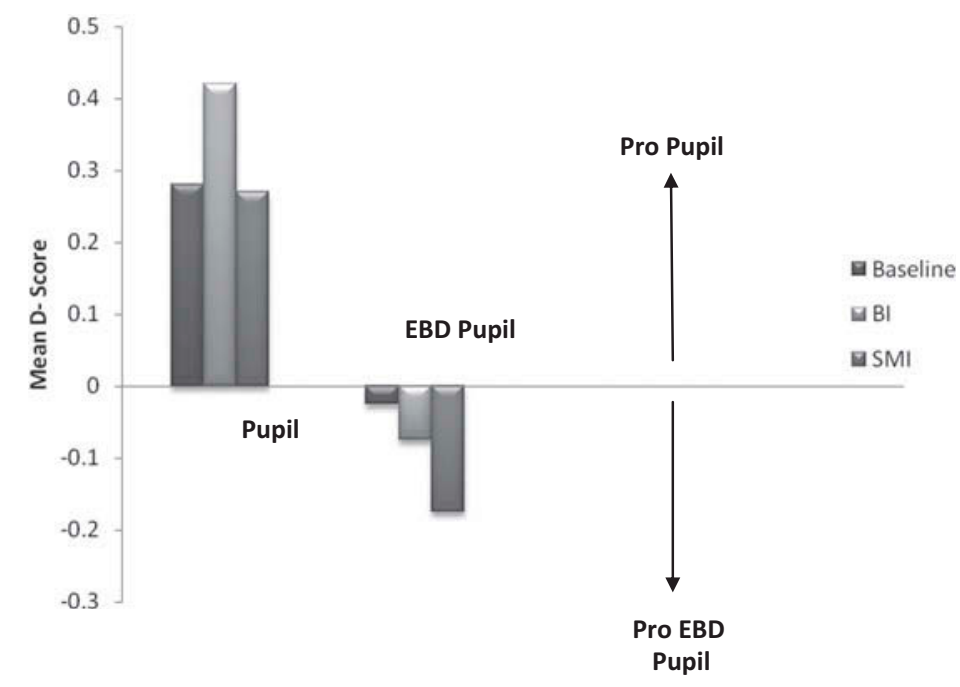

Figure 4. Mean D-scores for the mainstream teachers in the PUPIL and EBD PUPIL trial-type pairs on each IRAP exposure.

interventions did appear to reduce positivity towards PUPIL, with the greater effect associated with the SMI.

The IRAP data recorded with the teachers is presented in Figure 4. The baseline IRAP showed strong positivity toward PUPIL, with very minor positivity towards EBD PUPIL. While the BI enhanced PUPIL positivity, the SMI left it unchanged. However, both interventions enhanced positivity to EBD PUPIL, with the greater effect associated with the SMI.

\section{Results of explicit measures}

All of the quantitative data from the explicit measures was entered into SPSS (Version 11.5 ) and 'screened and cleaned' in preparation for full descriptive and statistical analyses.

\section{Attitudes to inclusion}

The results for each group on the ORMS sub-scales pre- and post-BI are presented in Table 3. For the purposes of analysis, strongly disagree/disagree responses were collapsed, as were strongly agree/agree. Both groups showed somewhat greater positivity in their general attitude towards inclusion after the BI (agreement of teachers in training changed from $59 \%$ to $70 \%$, with teachers' attitude moving from 52 to $55 \%$ ), and negativity in this regard decreased accordingly (disagreement of teachers in training went from 29 to $24 \%$ and that of teachers from 24 to 15\%). On the first part of the Emotional Reaction Scale, both groups showed decreased negativity from pre- to post-BI (teachers in training from 40 to $42 \%$, teachers from 50 to $57 \%$ ). On the second part of the Emotional Reaction Scale, teachers in training showed decreased negativity $(42 \%)$ and increased positivity $(33 \%)$ from pre- to post-BI, while teachers showed an $18 \%$ decrease in negativity and a $12 \%$ increase in positivity. On willingness to adapt teaching practice, both groups showed strong willingness to adjust (minimum $80 \%$ of both groups agreed, with teachers marginally less willing: $80 \%$ compared with $90 \%$ ) from the outset. 
Table 3. Results of ORMS sub-scales pre- and post-BI.

\begin{tabular}{|c|c|c|c|c|}
\hline & \multicolumn{2}{|c|}{ Teachers in training } & \multicolumn{2}{|c|}{ Mainstream teachers } \\
\hline & Pre-BI (\%) & Post-BI (\%) & Pre-BI (\%) & Post-BI (\%) \\
\hline \multicolumn{5}{|c|}{ General attitude towards inclusion } \\
\hline Disagree & 29 & 24 & 24 & 15 \\
\hline Undecided & 12 & 16 & 24 & 30 \\
\hline Agree & 59 & 70 & 52 & 55 \\
\hline \multicolumn{5}{|c|}{ Emotional reaction to inclusion of EBD child in classroom } \\
\hline Disagree & 37 & 18 & 33 & 23 \\
\hline Undecided & 23 & 40 & 17 & 20 \\
\hline Agree & 40 & 42 & 50 & 57 \\
\hline \multicolumn{5}{|c|}{ Emotional reaction to inclusion of otherwise excluded EBD child in classroom } \\
\hline Disagree & 60 & 18 & 37 & 21 \\
\hline Undecided & 18 & 27 & 14 & 18 \\
\hline Agree & 22 & 55 & 49 & 61 \\
\hline \multicolumn{5}{|c|}{ Willingness to adapt teaching practice } \\
\hline Disagree & 4 & 1 & 5 & 5 \\
\hline Undecided & 4 & 2 & 15 & 15 \\
\hline Agree & 92 & 97 & 80 & 80 \\
\hline
\end{tabular}

A series of paired-samples $t$-tests was used to evaluate the impact of the BI on the ORMS sub-scales. Significant differences from pre- to post- BI were recorded on teachers' general attitudes to inclusion $(p<0.001)$; the attitudes of teachers in training to the inclusion of a child with $\operatorname{EBD}(p<0.001)$; and the attitudes of teachers in training to inclusion of a previously excluded child with $\operatorname{EBD}(p<0.001$; all remaining $p \mathrm{~s}>0.151)$.

\section{Teacher efficacy}

The TES data for both groups pre- and post-BI are presented in Figure 5. On both exposures to the TES, both groups displayed strong self-reported efficacy (although the teachers in training were higher than teachers, 34 vs. 27, prior to intervention). Two paired-sample t-tests (one per group) revealed a significant effect for teachers $(p<008$ ?? but not for the teachers in training $(\mathrm{p}>0.536)$.

\section{Burnout}

Teachers' burnout levels were reduced after the SMI, with reductions in Dp and EE. Table 4 indicates that pre-SMI, teachers showed high burnout in terms of Dp, which changed to low burnout at post-intervention. Burnout in terms of EE was low at both pre- and post-SMI, but the high burnout in terms of PA at pre-SMI became moderate at post-intervention. A series of paired-sample t-tests evaluated the impact of the SMI on the three sub-scales, but no significant differences were recorded (all $p \mathrm{~s}>0.792$ ).

\section{$D A S S$}

Overall DASS scores (including depression, anxiety and stress) were initially high for teachers in training, but not for teachers (see Figure 6). The SMI appeared to reduce the former considerably and the latter marginally. As expected, two paired-sample $t$-tests (one per 


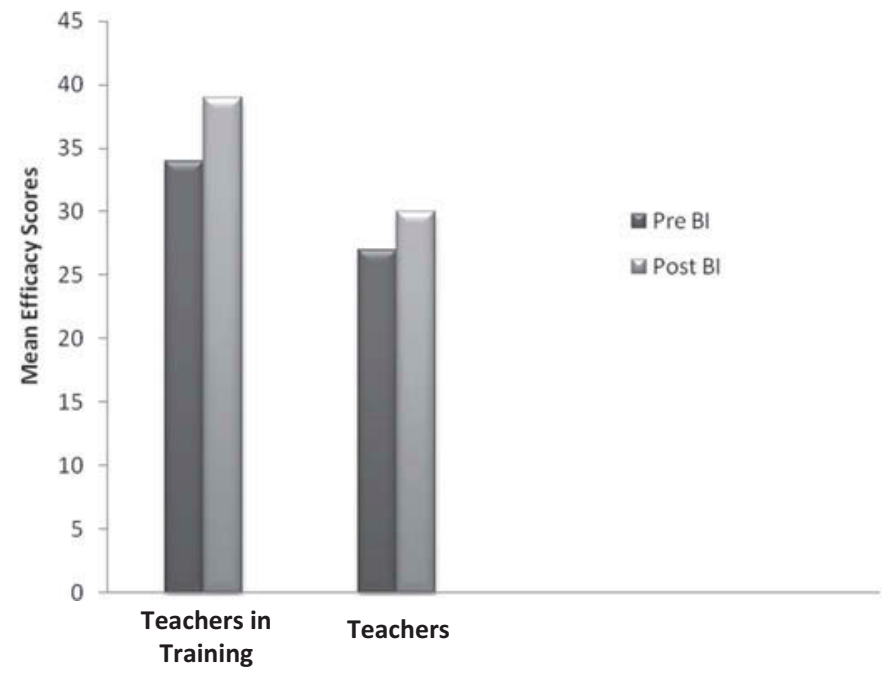

Figure 5. Mean TES scores for both groups pre- and post-BI.

Table 4. Results of MBI sub-scales pre- and post-SMI.

\begin{tabular}{lrll}
\hline Dp & \multicolumn{2}{c}{ EE } & PA \\
\hline Pre-SMI & & & \\
High (\%) & 80 & 12 & 27 \\
Moderate (\%) & 20 & 28 & 45 \\
Low (\%) & 0 & 60 & High burnout $^{\mathrm{a}}$ \\
High burnout & & \\
Post-SMI & & Low burnout $^{\mathrm{c}}$ & 20 \\
High (\%) & 12 & 8 & 28 \\
Moderate (\%) & 12 & 32 & 52 \\
Low (\%) & 76 & 60 & Moderate burnout $^{\mathrm{b}}$ \\
Low burnout & & & Low burnout \\
\end{tabular}

${ }^{\mathrm{a}}$ High burnout $=$ High EE/Dp and low PA.

${ }^{\mathrm{b}}$ Moderate burnout $=$ Moderate across the three sub-scales.

${ }^{\mathrm{c}}$ Low burnout $=$ Moderate EE/Dp and high PA.

group) revealed a significant effect for the teachers in training $(M=0.7 .66, \mathrm{SD}=7.5)$ $\left.t(20)=4.67, p<0.001, \eta_{\mathrm{p}}^{2} .53\right)$, but not for teachers $(p=0.598)$.

\section{$A A Q$}

Pre-SMI, both groups showed similar relatively low propensity towards acceptance of negative psychological content (i.e. low psychological flexibility, see Figure 7). Post-SMI, scores increased dramatically, showing much greater acceptance. Two paired-sample $t$-tests (one per group) revealed a significant effect for the teachers in training ( $M=7.66$, SD $\left.=7.5, t(20)=4.66, p<0.001, \eta_{\mathrm{p}}{ }^{2} .53\right)$, but not for teachers $(p>0.130)$.

In summary, the IRAP results for teachers indicated that the SMI enhanced their implicit positivity towards EBD PUPIL to a considerable extent $(0.025-0.175)$ and this 




Figure 6. The mean scores pre- and post-SMI on the DASS for both groups.

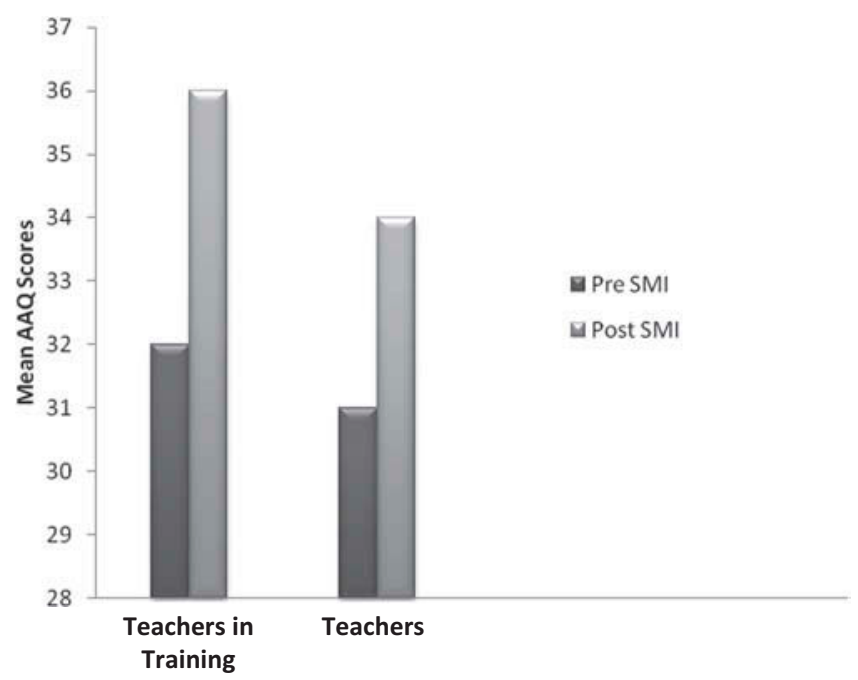

Figure 7. The mean scores pre- and post-SMI on the AAQ for both groups.

was greater than the impact recorded with the BI (see Figure 4). In contrast, the teachers in training showed implicit negativity towards EBD PUPIL (0.13) and this decreased (albeit marginally, see Figure 3 ) at post-BI (0.05) and post-SMI (0.06). Significant differences were recorded on teachers' general attitudes to inclusion $(p<0.001)$ and efficacy $(p<0.008)$. For teachers in training, significant effects were recorded in their attitudes to having a child with EBD and a previously excluded child with EBD in their classrooms (all $p \mathrm{~s}<0.001)$. There were also decreases in depression, anxiety and stress $(p<0.001)$, and an increase in psychological flexibility $(p<0.001)$. In conclusion, the current results indicate that a range of positive implicit and explicit outcomes were associated with the 
current BI and SMI package in terms of fostering more effective inclusion of pupils with EBD in mainstream education.

\section{Discussion}

\section{A focus on behavioural skills}

It is not surprising that self-perceptions of skill inadequacy have a detrimental effect on overt action, especially in the context of teaching (Sutherland et al. 2008). The aim of the BI employed here was to develop a programme that would assist mainstream post-primary teachers and teachers in training to effectively manage pupils with EBD. Our programme was specifically tailored towards a whole-school approach and was based upon the principles of applied behaviour analysis (and SWPBS in particular). The core components of the $\mathrm{BI}$ aimed to tackle deficits in identifying categories of EBD, the relationships between EBD and cognitive deficits, observing and assessing behaviour in the classroom and developing intervention strategies to manage challenging behaviour effectively.

From the outset, it was our belief that the majority of participants who volunteered did possess observable deficits in the target skills (i.e. they did not merely perceive themselves to have inadequate skills) and our observational evidence supported this conclusion. Specifically, the research findings from the Scanlon et al. (submitted) study highlighted the lack of specific training and support for teachers in this regard, which in turn has been found to reduce potential opportunities for positive interactions and increase possibilities for negative interactions. One of the findings from the current study highlighted the fact that participants were not aware of the specific behavioural and cognitive deficits of pupils with EBD, how these impacted on their behaviour or how they affected their potential learning trajectories. Consequently, the authors hypothesized that if implicit attitudes to pupils with EBD affected overt behaviour in the classroom, then increasing teachers' generic skills to manage these pupils more effectively in the mainstream classroom should provide positive outcomes for both parties. In short, although we were presented with very motivated and competent teaching professionals in both groups, from a strict behavioural management point of view, there were weaknesses in their knowledge and skills regarding managing human behaviour - especially when this was in some way physically or psychologically challenging. Of course, this profile is not at all unique to our sample. On the contrary, volunteering to participate probably resulted in the selection of two groups of highly motivated, diligent and open individuals, and this was certainly our ongoing impression of them. In short, they simply came to us with an inadequate history of behavioural training, which they perceived to be frustrating and worrisome enough to make them go to the trouble of getting help. Although, as behavioural psychologists (including a trained teacher), we were confident in our ability to offer participants sound behavioural training, we had initial concerns about the very short period of time allocated to this task. Teachers, on the whole, appear to receive little specific or focused behavioural training at any point in their careers and thus there was much to learn across a time frame of only eight hours. However, the outcomes for the BI across the majority of measures (with supporting evidence from the observations) indicated that participants had gained considerable behavioural knowledge and management skills. For example, participants quickly learned to operationally define individual pupil needs, discriminate the impact of their own behaviour on pupils, break learning and behavioural goals down into more achievable steps and maintain consistent behavioural contingencies and practice. Ironically, it is perhaps worrying that all participants reported the immediate and direct benefits of this training on their classroom 
management, and repeatedly suggested anecdotally that this should be made compulsory for all teachers in training.

\section{Teachers' personal development}

Workplace stress is now a significant health and safety issue (Bachkirova 2005). It is well established that teaching is a highly stressful profession (Cooper 2000) that correlates with high attrition rates across different ranks (Manassero et al. 2006), particularly high attrition amongst the recently qualified (DES 2005) and early retirement due to ill health (Bowers 2001).

The existing literature contains a number of favourable outcomes for stressmanagement programmes. For example, intensive counselling has been found to be effective in preventing the recurrence of work-related stress (Carlyle and Woods 2002 ). However, empirical evidence has also suggested that the mechanisms of change operated by stress management programmes vary considerably. According to Bond and Bunce (2000), acceptance (rather than avoidance) of undesirable thoughts and feelings is an important vehicle for positive change in dealing with work stress. Specifically, they reported that stress reduction was mediated by the acceptance of undesirable internal psychological content (rather than changing these directly) when they incorporated a strong acceptance element into a stress-management intervention designed for a commercial environment.

There is some empirical support for the relationship between experiential avoidance (as the opposite of acceptance) and work stress in the context of the teaching professions. Specifically, Biglan, Hayes, and Pistorello (2008) have reported that experiential avoidance in teachers is significantly correlated with depression, high stress, low living satisfaction and low self-efficacy. In formulating an effective treatment for these negative consequences of teaching, Biglan et al. (2008) argued that acceptance-based interventions that reduce experiential avoidance will likely ameliorate teachers' burnout and depression, while also increasing their work commitment and openness to evidence-based practice.

The SMI employed in the current research was conducted in line with similar views on the role of experiential avoidance and acceptance in teachers' mental and professional health. From the outset, we had a working assumption that teachers were not only struggling with pupils' challenging behaviour (which would be rectified by the BI), but that negative thoughts about themselves were a significant part of this struggle. Consider the following example which has been created by the authors to illustrate an understanding of this phenomena:

A teacher has an emerging history of negative interactions with a pupil. Naturally, this gives rise to resentment and thoughts like 'He is just trying to wind me up', 'I shouldn't have to put up with this' and 'I am better than this'. Of course, these thoughts are interpreted by the teacher as negative evaluations of a challenging (and probably needy) pupil and thus the next feeling to show up is guilt about a teacher having thoughts like that about a student. So, in the teacher's mind a great deal has happened (psychologically) in a short space of time. And the next time she sees him, there is even greater confusion, guilt and stress, because all of this is going around in her head.

In a high-stress context, it will be more difficult for the teacher to calmly decide what she might do with such a pupil and she will likely be even more sensitive to the pupil's challenges towards her. Furthermore, if she has self-guilt she will be unlikely to ask for help in case another teacher detects her guilty thoughts, because she naturally assumes that other teachers do not harbour similar negativity about pupils (in spite of what might be said overtly). And so the situation between teacher and pupil continues to spiral out of control, and a key mediator 
of this outcome is the teacher's guilt and related stress about her negative thoughts about the pupil. If one now adds the likelihood that the teacher also has little formal training in dealing with challenging behaviour, she will naturally also believe that she is incompetent. And so the stress continues, the teacher's self-efficacy deteriorates and the pupil's challenges increase.

The SMI employed here had a number of key elements specifically designed to facilitate acceptance of one's own psychology, of which professional life is an important part. First, we focused on openness to one's thoughts (especially negativity about others) and allowed participants to see that thoughts cannot be avoided and that there is much overlap in the types of thoughts that people have. For example, we asked our participants to write down the worst thought they ever had about a pupil and about teaching. The very act of writing these down often gives the person a sense of freedom from the thoughts, meaning they no longer have to expend effort on avoiding them. And of course, much of the shame falls away, because everyone is thinking along the same lines. A similar tack was taken with regard to the thoughts the participants had about themselves (e.g. 'I must be a terrible teacher if I am not perfect all the time').

Our second focus on the SMI was in order to enable participants to retrace their initial interest in and motivation for teaching in the first place, and to look at where these currently stood. Somewhat to our surprise, the majority of participants were still highly motivated about their profession. So our next step was to realign them with these personal values and consider why their actions had not always been in accordance with these values. In practically all cases, this shift away from values had resulted from low selfefficacy in behaviour management (i.e. they were having to deal with situations in which they were not trained) and guilt about their thoughts and feelings towards about challenging pupils.

\section{Self-efficacy in teachers}

Self-efficacy in teachers involves judgements of their capabilities in bringing about positive outcomes in student engagement and learning, including in relation to unmotivated and challenging pupils (Bandura 1997). In turn, teachers strongly discriminate their own behaviour in the classroom and are keenly aware of a mismatch between this and their expectations of classroom outcomes. When this mismatch is high, self-efficacy is reduced. In most cases this does not occur, because the majority of teachers are very good at teaching and managing classrooms - that is what they were trained to do. But when challenging behaviour occurs and they have not been trained to deal with it, low self-efficacy is almost unavoidable. Furthermore, because efficacy beliefs in teachers affect their investment in teaching and their levels of aspiration, it is likely that the goals they set for challenging children may be unnecessarily low (Bekle 2004). There is some indirect empirical support for this. For example, teachers with a strong sense of efficacy have been found to be more open to new ideas and more willing to experiment with new methods (Stein and Wang 1988), while exhibiting greater enthusiasm for teaching (Hall et al. 1992).

The current research contained a measure of self-efficacy in our participant samples, which we predicted would improve as a result of both interventions and would be a mediator of change. Indeed, the TES data revealed significant increases for the teachers. Furthermore, these participants demonstrated strong readiness to adjust their teaching practices when asked to make one change at post-BI.

Pre-BMI, we were somewhat surprised to find that the teachers in training exhibited higher levels of efficacy than teachers; we could only conclude that teachers faced ongoing 
challenges to keeping self-efficacy high. A number of factors support this conclusion. First, although the teachers in training are currently engaged in training, they are not present in the classroom to the same extent as teachers. Second, the teachers in training have ongoing support at their training institution, teachers do not. Third, teachers have a longer history of negative interactions with pupils, some of which remain salient for a long time. Fourth, over the past decade, teachers have encountered rapid and almost continuous educational reform.

\section{Where teacher stress meets burnout}

Burnout has been defined as a syndrome of high Emotional Exhaustion (EE) and Depersonalisation (Dp), with low Personal Accomplishment (PA) as outlined earlier. Although burnout is a feature of almost all professions, it is particularly prevalent in professions that involve direct dealings with other persons, and its prevalence in teachers is among the highest recorded (Biglan 2008). Specifically, it has been reported that Dp in teachers manifests itself in indifference and negativity towards pupils and low PA involves a sense of being no longer able to contribute to pupil development (Maslach, Jackson, and Leiter 1996).

A recent study by Talmor, Reiter, and Feigin (2005) examined burnout in mainstream teachers who worked directly with pupils with SEN. The results indicated that the following environmental factors correlated with burnout: teachers believing that inclusion resulted in more disciplinary difficulties, poor school-wide support and a high percentage of SEN pupils in the classroom. Interestingly, the researchers also reported that burnout was high among teachers who had positive perceptions and high expectations of inclusion, because their ideals regarding inclusion are not likely to be met. In summary, Talmor et al. (2005) argued that teacher burnout is almost inevitable when there is a gap between what is being demanded and how this is provided for. Inclusion is a primary example of such a scenario.

The current research employed the MBI as a measure of potential burnout in teachers. The results indicated that these individuals were experiencing moderate overall levels of burnout. Nonetheless, although we may have expected a ceiling effect, post-SMI scores showed enhanced PA and reduced Dp outcomes. This finding suggests that it is not necessary (or even wise) to wait until teacher burnout is high to intervene and enhance PA and reduce Dp.

\section{Inclusion of pupils with SEN}

The current data was consistent with previous evidence that teachers have positive implicit attitudes towards pupils, with preliminary evidence of their reduced favourability towards pupils with EBD (Scanlon et al. submitted). The IRAP findings here firmly support these outcomes. One issue that was of particular interest was the initial difference in implicit attitudes to EBD observed with the teachers vs. teachers in training. In short, the former were more favourable, yet one might have expected the reverse given that the teachers in training are only starting out in the teaching profession. However, there is also existing IRAP evidence that professional experiences actually enhance implicit attitudes to the population with whom one works as a professional, rather than the experience (which invariably contains some negative interactions) suppressing positivity or fostering negativity (Coogan, Barnes-Holmes, and Barnes-Holmes 2008). However, in the context of teachers interacting with EBD pupils, there may be an important interaction amongst other variables - such 
as number of SEN children in class and level of teacher experience - that influence the nature and extent of teachers' implicit attitudes to this population. Future research will be needed to tease apart these relative influences, which might also add insight into potential adjustments necessary to intervention packages.

\section{Conclusions}

The current research adopted a perhaps non-traditional approach to teachers' situation, particularly with regard to the need to include children with EBD in mainstream education. Across several previous studies, the current researchers had learned of two key features of teaching in a modern Irish environment, both of which contributed to the present programme of work. First, we had come to conclude that teachers, in spite of their immense motivation and educational competence, lacked critical skills for managing challenging behaviour. Second, self-discriminations of these deficits and the classroom and learning outcomes that resulted from them likely reduced self-efficacy and enhanced stress and susceptibility to more significant psychological problems, which, taken together, could ultimately lead to professional burnout. It seemed to us that it would be shortsighted to tackle only one of these problems; hence, our two-fold intervention package addressed both issues and the interaction between them. The data, which are still in many respects preliminary (e.g. small sample sizes), offer sound support for our conclusions and, more importantly, indicated the ability to generate positive outcomes on both fronts in a short space of time and without adding greatly to teachers' already heavy workloads. Naturally, these outcomes also suggest future directions for working with the pupils themselves (pilot work on this type of research is already underway by the current authors), although that was not the focus of this research. However, the findings from this project offer considerable optimism in relation to the current challenges regarding how children with EBD can be effectively integrated into mainstream education.

Numerous aspects of the current programme of research have implications for teacher education and the field's continuing professional development. The research had two key strands designed to tackle the behavioural and psychological aspects of teaching children with EBD in a mainstream environment. Traditionally, interventions in this area have been sparse and where these are available the best programmes offer some form of behavioural training, which is often not open to teachers already struggling with growing professional demands. The importance of this, however, is highlighted further by the potential negative psychological outcomes that arise for both teachers and pupils when teachers are forced to educate in a challenging environment in which they have no history of formal training. Hence, the current research had a stress-management feature that allowed teachers to take time to reflect on their own psychology and how it relates to their teaching. Although delivery of stress-management programmes is a growing trend, there remain few specifically focused on teachers and there is little or no empirical evidence of their efficacy in this regard. The present data offer support for the utility of the two-fold package we employed here and our participants were unanimous in suggesting that it should be incorporated into teacher training and continuing professional development. The positive outcomes across the explicit and implicit measures, as well as the very brief nature of the interventions, support the feasibility of this suggestion. Critically, at a broader level, these findings have important implications for the rhetoric on inclusion and how teachers in mainstream education are supported to effectively include pupils who have more complex and challenging needs. 


\section{Acknowledgements}

The National Council for Special Education (NCSE) funded this research. Responsibility for the research (including any errors or omissions) remains with the authors. The views and opinions contained in this report are those of the authors and do not necessarily reflect the views or opinions of the NCSE.

\section{References}

Antonak, R., and B. Larrivee. 1995. "Psychometric Analysis and Revision of the Opinions Relative to Mainstreaming Scale." Exceptional Children 62: 139-149.

Avramidis, E., and B. Norwich. 2002. "Teachers' Attitudes Towards Integration/Inclusion: A Review of the Literature." Journal of Special Needs Education 17: 129-147.

Bachkirova, T. 2005. "Teacher Stress and Personal Values: An Exploratory Study." School Psychology International 26: 340-351.

Bandura, A. 1997. Self-Efficacy: The Exercise of Control. New York: Freeman.

Barnes-Holmes, D., Y. Barnes-Holmes, E. Hayden, R. Milne, P. Power, and I. Stewart. 2006. "Do You Really Know What You Believe? Developing the Implicit Relational Assessment Procedure (IRAP) as a Direct Measure of Implicit Beliefs.” The Irish Psychologist 32: 169-177.

Bay, M., and T. H. Bryan. 1991. "Teachers' Reports of Their Thinking About At-Risk Learners and Others." Exceptionality 2: 127-139.

Bekle, M. 2004. "Knowledge and Attitudes about Attention-Deficit Hyperactivity Disorder (ADHD): A Comparison Between Practicing Teachers and Undergraduate Education Students." Journal of Attention Disorders 7: 151-160.

Biglan, A. 2008. "Teacher Stress and Collegiality: Overlooked Factors in the Effort to Promote Evidence-Based Practices." Association for Behaviour Analysis International 31: 3.

Biglan, A., S. C. Hayes, and J. Pistorello. 2008. "Acceptance and Commitment: Implications for Prevention Science." Prevention Science 31: 3-10.

Bond, F., and D. Bunce. 2000. "Mediators of Change in Emotion-Focused and Problem-Focused Worksite Stress Management Interventions." Journal of Occupational Health Psychology 5: 156-163.

Bond, F. W., S. C. Hayes, R. A. Baer, K. H. Caprenter, N. Guenole, H. K. Orlutt, T. Walts, and R. D. Zettle. 2011. "Preliminary Psychometric Properties of the Acceptance and Action Questionnaire - 11: A Revised Measure of Psychological Flexibility and Experiental Avoidance." Behaviour Therapy 42: 676-688.

Bowers, T. 2001. "Teacher Absenteeism and Ill Health Retirement: A Review." Cambridge Journal of Education 31: 135-157.

Butler, S., and M. Shevlin. 2001. "Creating an Inclusive School: The Influence of Teacher Attitude." Irish Educational Studies 1: 125-135.

Carlyle, D., and P. Woods. 2002. Emotions of Teacher Stress. Stoke-on-Trent: Trentham Books.

Clough, P., and G. Lindsay. 1991. Integration and the Support Service. Slough: NFER.

Cohen, R., D. Kincaid, and K. Childs. 2008. "Measuring School-Wide Positive Behaviour Support Implementation: Development and Validation of the Benchmarks of Quality." Journal of Positive Behaviour Interventions 9: 203-213.

Coogan, F., Y. Barnes-Holmes, and D. Barnes-Holmes. 2008. "The Characteristics of Implicit Attitudes in Adults Working in Disadvantaged Communities." PhD diss., The National University of Ireland Maynooth.

Cooper, P. and B. Jacobs. 2011. Evidence of Best Practice Models and Outcomes in the Education of Children with Emotional Disturbance/Behavioural Difficulties. An International Review. Research Report No. 7. Trim: National Council for Special Education.

Cooper, C. L. 2000. "Stress at Work." http://www.channel4.com/health/microsites $/ / 0$ 9/4health/stress/saw_teachers.html.

Crawford, J. R., and J. D. Henry. 2003. "The Depression Anxiety Stress Scales (DASS): Normative Data and Latent Structure in a Large Non-Clinical Sample." British Journal of Clinical Psychology 42: 111-131.

Cullen, C., D. Barnes-Holmes, Y. Barnes-Holmes, and I. Stewart. 2009. "The Implicit Relational Assessment Procedure (IRAP) and the Malleability of Ageist Attitudes." The Psychological Record 59: 591-620. 
Daniels, H., T. Cole, and N. Reykebill. 1999. Emotional and Behavioural Difficulties in Mainstream Schools. London: DfEE.

Department of Education and Science. 1993. Report of the special education review committee. Dublin: Government Publications.

Department of Education and Science. 1998. Education Act. Dublin: Government Publications.

Department of Education and Science. 2004. Education for Persons with Special Educational Needs. Dublin: Government Publications.

Department of Education and Science. 2006. School Matters: The Report of the Task Force on Student Behaviour in Second Level Schools. Dublin: Government Publications.

Department of Education and Skills (DES). 2005. Circular 012/05. DES.

Evans, J., A. Harden, and A. Thomas. 2004. "What Are Effective Strategies to Support Pupils with Emotional and Behavioural Difficulties (EBD) in Mainstream Primary Schools? Findings from a Systematic Review of Research." Journal of Research in Special Educational Needs 4: 2-16.

Greenwald, A. G., and M. R. Banaji. 1995. "Implicit Social Cognition: Attitudes, Self-esteem and Stereotypes." Psychological Review 10: 4-27.

Griffin, S., and M. Shevlin. 2007. Responding to Special Educational Needs. Dublin: Gill \& Macmillan.

Hall, B., W. Burley, M. Villeme, and L. Brockmeier. 1992. “An Attempt to Explicate Teacher Efficacy Beliefs Among First Year Teachers." Paper presented at the annual meeting of the American Educational Research Association, San Francisco, CA.

Hastings, R. P., and S. Bham. 2003. "The Relationship Between Student Behaviour Patterns and Teacher Burnout." School Psychology International 24: 115-127.

Hastings, R. P., and S. Oakford. 2003. "Student Teachers' Attitudes Towards the Inclusion of Children with Special Needs." Educational Psychology 23: 87-94.

Hayes, S., J. Luoma, F. Bond, A. Masuda, and A. J. Lillis. 2006. "Acceptance and Commitment Therapy: Model, Processes and Outcomes." Behaviour Research and Therapy 44: 1-25.

Kauffman, J. M. 1999. "The Role of Science in Behaviour Disorders." Behavioural Disorders 24: $265-272$.

Lambe, J., and R. Bones. 2006. "Student Teachers' Attitudes to Inclusion: Implications for Initial Teacher Education in Northern Ireland." International Journal of Inclusive Education 10: 511 527.

Larsen, S. R., M. M. Steele, and W. Sailor. 2006. "The Relationship of School-Wide Positive Behavior Support to Academic Achievement in an Urban Middle School." Psychology in the Schools 43: 701-712.

Lazarus, R. S., and S. Folkman. 1984. Stress Appraisal and Coping. New York: Springer.

Lovibond, S. H., and P. F. Lovibond. 1995. "The Structure of Negative Emotional States: Comparison of the Depression Anxiety Stress Scales (DASS) with the Beck Depression and Anxiety Inventories." Behaviour Research and Therapy 33: 335-343.

Luiselli, J., R. Putnam, M. Handler, and A. Feinberg. 2005. "Whole-School Positive Behaviour Support: Effects on Student Discipline Problems and Academic Performance." Educational Psychology 25: 183-198.

Manassero, M., E. Garcia-Buades, G. Torrens, C. Ramis, A. Varquex, and V. A. Ferrer. 2006. "Teacher Burnout: Attributional Aspects." Psychology in Spain 10: 66-74.

Maslach, C., S. Jackson, and M. Leiter. 1996. Maslach Burnout Inventory Manual. 3rd ed. California: CPP Inc.

Nitnas, K. M., A. Neila, E. Nikolaidou, S. Papadimitriou, I. Papadopoulou, A. Fasoulas, and C. Hatzikonstantinidis. 2006. "Inclusion and Challenging Behaviours: Greek General Educator's Perspectives." The Behaviour Analyst Today 1: 84-95.

Power, P. M., D. Barnes-Holmes, Y. Barnes-Holmes, and I. Stewart. 2009. "The Implicit Relational Assessment Procedure (IRAP) as a Measure of Implicit Relative Preferences: A First Study." The Psychological Record 59: 621-640.

Roddy, S., I. Stewart, and D. Barnes-Holmes. 2010. "Anti-Fat, Pro-Slim, or Both? Using Two Reaction Time Based Measures to Assess Implicit Attitudes to the Slim and Overweight." Journal of Health Psychology 15: 416-425.

Scanlon, G., Y. Barnes-Holmes, D. Barnes-Holmes, and I. Stewart. Submitted. “ The Implicit and Explicit Attitudes of Teachers to Pupils with Emotional and Behavioural Difficulties in Mainstream Education." The Psychological Record. 
Scanlon, G., and S. McGilloway. 2006. "Managing Children with Special Needs in the Irish Education System: A Professional Perspective." Journal of the Irish Association of Teachers in Special Education (REACH) 1: 81-94.

Scott, T. M. 2007. "Issues of Personal Dignity and Social Validity in School-Wide Systems of Positive Behaviour Support." Journal of Positive Behaviour Interventions 9: 102-112.

Scruggs, T. E., and M. A. Mastropieri. 1996. "Teachers Perceptions of Mainstreaming-Inclusion, 1958-1995: A Research Synthesis." Exceptional Children 63: 59-74.

Stein, M., and W. Wang. 1988. "Teacher Development and School Improvement, the Process of Teacher Change." Teaching and Teacher Education 4: 171-187.

Sugai, G., R. H. Horner, G. Dunlap, M. Heineman, T. J. Lowis, C. M. Nelson, T. Scott, et al. 2000. "Applying Positive Behaviour Support and Functional Behavioural Assessment in Schools." Journal of Positive Behaviour Interventions 2: 131-143.

Sutherland, K., T. Lewis-Palmer, J. Stichter, and P. Morgan. 2008. "Examining the Influence of Teacher Behaviour and Classroom Context on the Behavioural and Academic Outcomes for Students with Emotional or Behavioural Disorders." The Journal of Special Education 4: 223-233.

Talmor, R., S. Reiter, and N. Feigin. 2005. "Factors Relating to Regular Education Teacher Burnout in Inclusive Education.” European Journal of Special Needs Education 20: 215-229.

Travers, J. 2006. "Perceptions of Learning-Support Teachers and Resource Teachers of Each Other's Role in Irish Primary Schools." Irish Educational Studies 25: 155-169.

Tschannen-Moran, M., and A. Woolfolk Hoy. 2001. "Teacher Efficacy: Capturing an Elusive Construct." Teaching and Teacher Education 17: 783-805. 